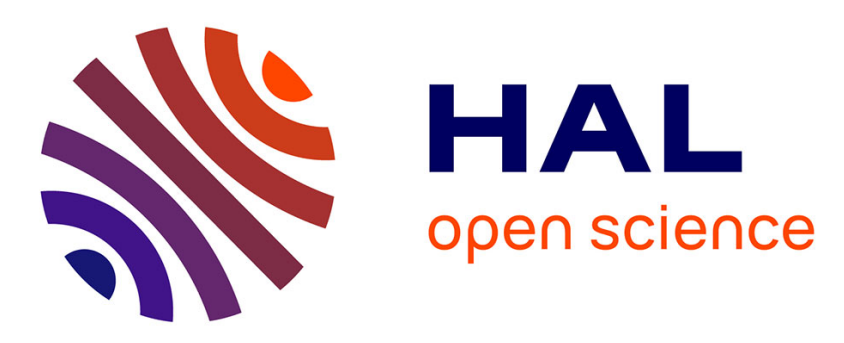

\title{
An integrated multifractal modelling to urban and regional planning
}

Pierre Frankhauser, Cécile Tannier, Gilles Vuidel, Hélène Houot

\section{To cite this version:}

Pierre Frankhauser, Cécile Tannier, Gilles Vuidel, Hélène Houot. An integrated multifractal modelling to urban and regional planning. Computers, Environment and Urban Systems, 2018, 67, pp.132-146. 10.1016/j.compenvurbsys.2017.09.011 . hal-01614652

\section{HAL Id: hal-01614652 \\ https://hal.science/hal-01614652}

Submitted on 28 May 2018

HAL is a multi-disciplinary open access archive for the deposit and dissemination of scientific research documents, whether they are published or not. The documents may come from teaching and research institutions in France or abroad, or from public or private research centers.
L'archive ouverte pluridisciplinaire HAL, est destinée au dépôt et à la diffusion de documents scientifiques de niveau recherche, publiés ou non, émanant des établissements d'enseignement et de recherche français ou étrangers, des laboratoires publics ou privés. 


\title{
An integrated multifractal modelling to urban and regional planning
}

\author{
Pierre Frankhauser, Cécile Tannier, Gilles Vuidel, Hélène Houot \\ Published in Computers, Environment and Urban Systems \\ vol. 67 (2018), pp. 132-146.
}

\begin{abstract}
In this paper, we propose a conceptual framework for the design of multifractal urban or regional development plans that adhere to five planning principles: hierarchical polycentric urban development; transit-oriented development; locally dense residential development; penetration of green areas into built-up areas across several nested scales; preservation of interconnected networks of natural and green areas having various sizes. This conceptual planning framework is based on multifractal spatial modelling, which is intrinsically multiscalar. The GIS-based software application Fractalopolis (current version 1.0) is used to apply this conceptual framework to real-world case studies. Fractalopolis helps to define where to create new housing and new facilities in accordance with the planning principles set out above. We use Fractalopolis to create a multifractal development plan for a medium-sized French metropolitan area, namely Besançon, for the year 2026. This plan allows a realistic "soft" transformation the Besançon metropolitan area in keeping with the five planning principles set out above and makes the region more multifractal.
\end{abstract}

\section{Keywords}

Urban planning; multifractal; central places; Iterative Function Systems; computer-based simulation

\section{Introduction}

The consequences of urban sprawl have been at the heart of planning concerns for several decades now. The construction of residential areas far from jobs and facilities is considered to have caused an increase in the number and length of trips by car as well as increased congestion and pollution. This is mainly due to greater distances to be covered to accede to jobs and facilities as well as the inefficiency of public transport along peripheral routes (Cervero 1996, Cervero and Kockelman 1997, Franck and Pivo 1994). Moreover, individual housing, which prevails in city outskirts, is seen as a source of excessive and worrying consumption of space, especially because the scattered spatial distribution of residential areas entails the construction of new roads which fragment natural areas and agricultural land. Land consumption for residential development and the associated construction of transport facilities, as well as the traffic induced and other human disturbances, all threaten biodiversity.

Classically, planning recommendations for limiting the negative effects of urban sprawl are: compact urban development, polycentric developement, New Urbanism and Transport- 
Oriented Development, Concentrated Decentralization, greenways and green corridors. Yet, when designing urban development plans, these recommendations can hardly been applied jointly, mainly because of the absence of a formal integrative framework.

In this paper, we propose a multifractal modelling, which is intrinsically multiscale and aims to combine these planning principles within a single coherent framework. The value of fractal urban development on a local or an intermediate scale has already been pointed out, e.g. by Frankhauser (1994, 2008) and Salingaros (2004). Fractal residential development, which allows intra-urban non-built areas to be preserved, meets the expectations of the population better than a uniformly dense urban form (Cavailhès et al. 2004, Tannier et al. 2012). Moreover, if the local fractal dimension of residential development is high enough, it averts the loss of ecological habitats and concomitantly avoids the barrier effect of built areas (Tannier et al. 2016). Multifractal modelling extends the idea of fractal urban development up to the regional scale. It also introduces greater diversity in the sizes of both urban and nonurban areas (Cavailhès et al. 2010, Frankhauser 2015).

In order to create multifractal plans for real-world situations, the multifractal modelling process has been integrated into a GIS-based software application named Fractalopolis. The preliminary stage in the design of this application (version 0.6.1) is described in Yamu and Frankhauser (2015). Here we present the completed version 1.0 of Fractalopolis.

The paper is organized as follows. Section 2 provides an overview of planning recommendations classically advocated to limit the negative effects of urban sprawl. From these recommendations, we take on five key planning principles. Section 3 sets out the theoretical basis of multifractal modelling for planning purposes. Section 4 describes how it can be applied using Fractalopolis 1.0 in the case of the urban region of Besançon (eastern France). Section 5 concludes the paper.

\section{Overview of planning recommendations classically advocated to limit the negative effects of urban sprawl}

Compact urban development is usually seen as the most efficient solution for limiting urban sprawl (see e.g. Krier 1998, Duany, Plater-Zyberk and Speck 2001). It is characterized by high built densities, uniformity, and sharply contrasting boundaries (Geurs and Van Wee 2006). Yet the impact of density on car use is not straightforward and may sometimes be contradictory, especially with respect to trip frequencies (Hall 1997, Neuman 2005). Moreover, as pointed out by Schwanen et al. (2004), increasing density in residential zones may prompt households to move to lower density areas. Hence a compact city policy may actually encourage urban sprawl in the long term. Neuman (2005) reports that residents show no long-run preference for dense centres as in Boston, Baltimore, or San Francisco. The shrinking city phenomenon in eastern Germany (Bontje 2005) or the exodus from the Corbusier skyscrapers in France show that density cannot be imposed - at least in countries where places of residence can be freely chosen. Planners tend to favour urban renewal and apply urban containment strategies to produce compact cities. Common planning tools for urban containment strategies include Urban Growth Boundaries and greenbelts. Yet such strategies may cause leapfrogging in urban development (Vyn 2012, Peeters et al. 2015). Siedentop et al. (2016) claim this undesirable phenomenon is likely to occur if growth restrictions are limited to core areas of city regions. In such cases, higher land prices may cause urbanization to spread to communities where no such regulations apply. Consequently, less dense suburban or exurban areas should be incorporated into growth control schemes. 
In conjunction with urban containment strategies, polycentrism may limit urban sprawl through non-uniform spatial distribution of new urban developments (Camagni and Gibelli 1997). A comparison of several French metropolitan areas shows that commuting distances are held down more effectively in polycentric agglomerations than in monocentric ones (Aguilera and Mignot 2004). However, polycentric urban configurations are usually the outcome not of strategic planning but of market-driven dynamics. Fujita and Ogawa (1982) first demonstrated that, for a growing population, urban sub-centres emerge when transport costs exceed a critical threshold. This was confirmed by empirical investigations by McMillen and Smith (2003). Very early on, Christaller (1933) proposed a deductive explanation for the emergence of a hierarchy of sub-centres by linking service and commercial offers, market areas, and frequency of recourse to them. In Christaller's system, a hexagonal spatial distribution of central places ensures that consumers living in urban centres of a low hierarchical level can obtain goods and products they do not often need from one of the three higher-level neighbouring centres. Central place theory is often thought of as a descriptive scheme with no micro-economic foundation (Krugmann 1995). A crucial point for debate is price elasticity, which varies with distance in spatial price theory whereas central place theory assumes that the substitutability of goods and thus price elasticity is constant (Fittkau 2004, Fujita and Thisse 2002).

Other urban planning models have been proposed with a focus on the use of public transport networks and the attractiveness of intra-urban space, especially New Urbanism and TransportOriented Development (Calthorpe 1993), and Concentrated Decentralization (Schwanen, Dijst and Dieleman 2004). In Transit-Oriented Development, transit nodes serve a predominant function in the urban system; they concentrate all kinds of facilities as well as public spaces offering green amenities. The urban system is organized hierarchically, combining urban centres of various functional levels, which is reminiscent of Christaller's central place system. In each urban centre, density decreases from the centre outwards. New Urbanism supplements the TOD planning strategy by focusing on intra-urban design. The traditional design of old centres of European cities is the benchmark. In the Netherlands, the development plans of a couple of new towns located in the Randstad, Holland and encompassing ancient villages provides a good illustration of the application of TOD and New Urbanism planning concepts. Almere is one of those two towns; it now has 196,290 inhabitants. Its urban area consists of three main centres. A railway station is located in each centre and is the starting point of a pedestrian boulevard with shops and restaurants on the ground level and apartments and multi-family housing in the upper storeys. The public bus system benefits from separate bus lanes. A segregated system of bike lanes generally passes under the roads. A green network is accessible for residents within a radius of $500 \mathrm{~m}$ and includes large forested and natural areas located a few minutes’ bike-ride away (Beatley 2012).

Greenways policy is another planning concept applied quite early on in northern European countries. Inspired by the spatial development of Berlin, which was linked to the construction of an efficient suburban railway, Eberstadt, Möhring, and Petersen (1910) suggested concentrating urban development in radial sectors along public transport routes. In-between these urbanized sectors, green sectors penetrate into the city providing residents with easy access to green areas. Similarly, the development plan proposed by Schmidt (1912) for the Ruhr region separates the different towns of the region by a network of green areas providing recreational areas. Another well-known example is Copenhagen's finger plan, which features development routes served by public transport and green lanes in-between these routes. The climatic relevance of greenways has been emphasized in many articles. As intra-urban parks and squares are mainly beneficial to microclimates (Kong 2014), they should ideally be 
connected to outlying rural zones via ventilation corridors providing cool air at night (von Haaren and Reich 2006, Kuttler 2011, Sachsen et al. 2013).

As pointed out by Bryant (2006), greenways can prevent landscape fragmentation and preserve biodiversity if they are not designed in a "piecemeal fashion". Borgström et al. (2006) have suggested that the efficient management of green areas in an urban setting requires a multiscale strategy ranging from local up to regional level. Urban landscape management should ideally combine land-use policy with nature conservation across scales. Yet urban and ecological processes intertwine in a complex manner. Gaining in one characteristics on a given scale, e.g., meeting demand for housing by increasing housing density, comes partly at the expense of other characteristics, e.g. the local availability of open space and biodiversity on the regional scale (Wissen Hayek et al. 2015). Moreover, allowing wildlife into residential neighborhoods generates negative externalities, and it is unclear to what extent these externalities affect urban spatial dynamics (Toger et al. 2015). Soga et al. (2015) have also identified a potential conflict in the design of cities between the urban form that is most desirable for the direct protection of regional biodiversity (i.e. land sparing) and the form that best promotes people's experience of nature and so their support for its wider protection (i.e. land sharing).

In general, small ecological patches, long inter-patch distances, and lack of ecological connectivity make for poor conditions for preserving biodiversity (Collinge 1996, Forman 1995). On the scale of an urban region, urban sprawl may entail increased traffic induced by daily trips between the centre(s) and the outskirts and consequently a barrier effect of transport networks (Fu et al. 2010, Gurrutxaga et al. 2010). On a local scale, dense urban development may avert the loss of ecological habitats (Conway 2009) but concomitantly increase the barrier effect of built areas (Aguilera et al. 2011). Conversely, loose urban development increases landscape fragmentation but the barrier effect of built areas may be reduced if the urban boundary remains comparatively fuzzy (Czamanski et al. 2008) and/or if urban patterns are examined at a very fine scale (Toger et al. 2016). Maintaining or creating interconnected networks of natural and green areas having various sizes can help to preserve biodiversity. Yet Oliveira et al. (2011) have pointed out that intertwining the urban fabric with local ecological habitats may be desirable or not according to the local context. For some cities, urban biodiversity may comport with the surrounding biodiversity. In this case, leaving corridors that link the urban biodiversity with the surrounding biodiversity is positive. For other cities, this should be avoided, at least for some ecological species. Besides, despite the negative impacts of urbanisation on biodiversity, especially loss of ecological habitats and landscape fragmentation, the urban environment is ecologically highly dynamic (Angold et al. 2006; Savard et al. 2000). For instance, urban habitats can contain a remarkable wealth of pollinator species (i.e. flower-visiting insects) (Baldock et al. 2015). Last but not least, biodiversity in urban areas can be higher than in the surrounding rural areas (Qureshi and Breuste 2010).

This short overview illustrates the difficulty to achieve a sustainable urban development. Involved phenomena are numerous and diverse, and their relations are complex and still partially unknown. Moreover, some planning recommendations may contradict one another. Nevertheless, it seems possible to retain five key principles that generally have more advantages than disadvantages: 
- hierarchical polycentric urban development in order to improve accessibility to a large range of facilities (i.e. shops and services as well as leisure infrastructures and green areas frequented daily to rarely);

- transit-oriented development that concentrates residential growth along the public transport axes and so promotes the use of public transport;

- locally concentrated residential development to favour good access to frequently used shops and services accessible by soft modes, like cycling or walking;

- the penetration of green areas into built-up areas at several nested scales to ensure good access to green areas for residents and to create ventilation corridors to outer rural zones providing good air quality and cool air at night;

- the preservation of interconnected networks of natural and green areas having various sizes to preserve biodiversity.

Some general planning concepts integrate a number of these five planning recommendations and provide quantitative guidelines for their implementation. Howard's Garden City (1898) is perhaps the most complete and integrative of them. Yet its recommended pattern is a polycentric system of compact cities surrounded by green belts, the drawbacks of which have been previously set out. Thus in practice, when designing urban development plans, the five key planning principles can hardly been applied jointly because of the absence of a formal integrative framework. The multifractal modelling proposed below enables us to combine them within a single coherent framework.

Figure 1. Multifractal planning: a theoretical example.

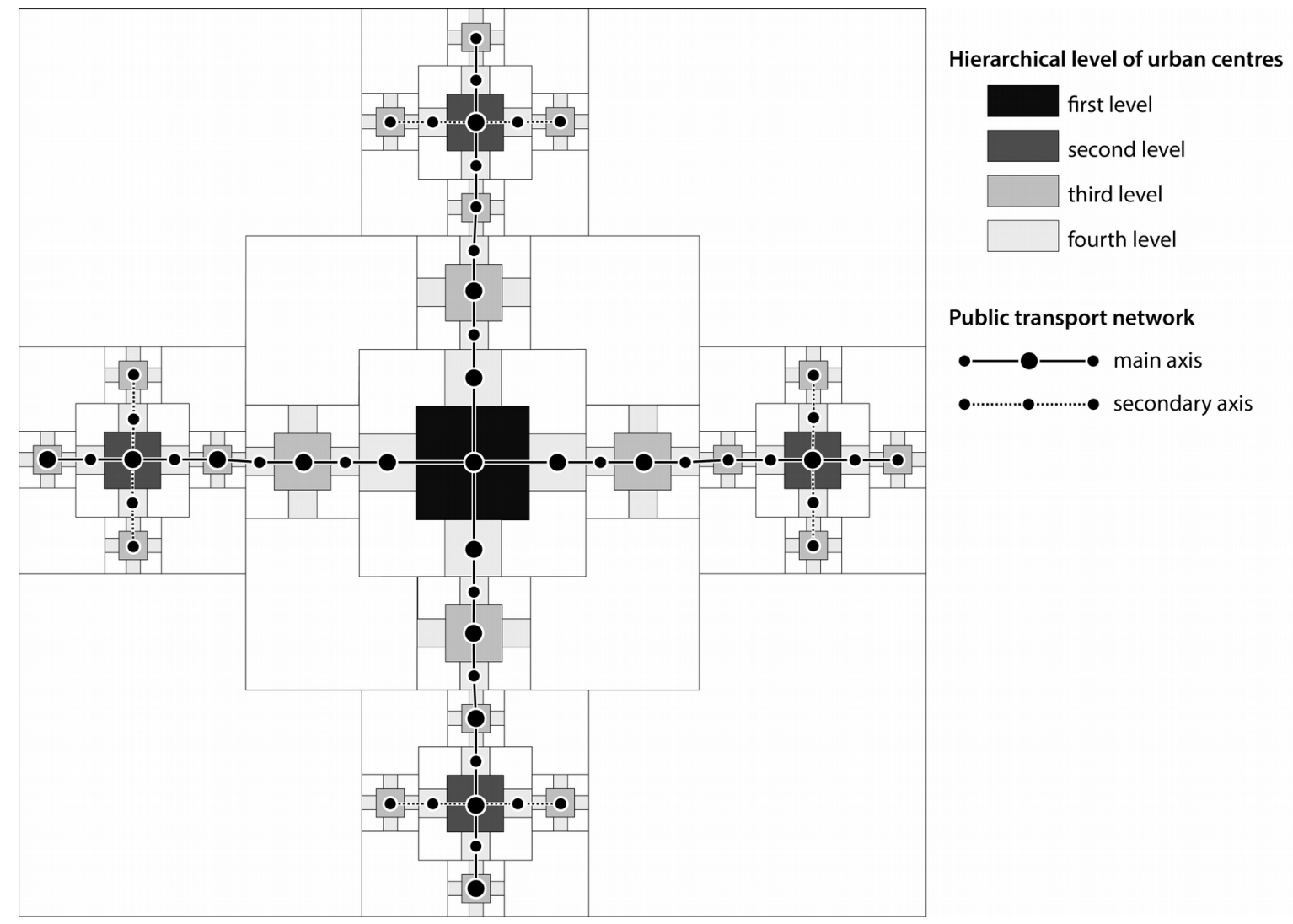




\section{Multifractal planning: theoretical description}

The chosen theoretical reference model is a multifractal Sierpinski carpet representing a hierarchical nesting of central places (i.e. urban centres) (Figure 1). Two types of zone are distinguished, those available for urbanization and those for which only weak development or no development at all is permitted (in white color on Figure 1). This allows avoiding uncontrolled sprawl and meets the principle of "Concentrated Decentralization".

A public transport network is ideally structured by a nested radiating concentric logic. Urban centres are located close to stops on this public transport network. This corresponds to the logic of transit-oriented development and goes beyond the purely axial planning concepts of Northern European cities.

The multifractal Sierpinski carpet also complies with a central place logic, which is intrinsically polycentric. Through its strict concentric organization, it minimizes the distances from small centres to bigger ones according to inhabitants' respective potential frequency of recourse to them. A single main centre is located at the heart of the spatial system and contains the entire range of retail stores and facilities. This main centre is surrounded by second-order sub-centres containing shops and services to which inhabitants resort monthly, weekly, and daily. Each of these sub-centres is surrounded by third-order sub-centres offering facilities frequented weekly and daily. Those in turn are surrounded by centres with goods and services for daily use only. Hence mean trip distances correspond to the frequency of recourse. A coding system is used to distinguish the different urban centres by their functional hierarchical level (section 3.1).

The population is distributed in line with a hierarchical nested logic, in which higher-level urban centres are more densely populated than lower-level ones (section 3.3). For a given functional level, urban centres located close to high-level centres are larger than those located close to low-level centres. This seems more realistic than Christallers' model in which cities of the same functional level have the same population whatever their relative location.

An interconnected system of natural and green areas is organized in accordance with a hierarchical nesting of large areas such as forests down to small areas providing green amenities very close to residential locations (section 3.2). The existence of radial greenways that penetrate into built-up areas on several nested scales enlarges and generalizes the logic of development adopted by several Northern European cities (Copenhagen, Berlin, Hamburg, Helsinki, Stuttgart). Moreover, the existence of large interconnected networks of natural and green areas having various sizes favors biodiversity preservation.

\subsection{Multifractal hierarchy of urban centres}

Figure 2 illustrates how the multifractal Sierpinski carpet is constructed step-by-step. First, the whole urban region under consideration is covered by a square of length and width $L$. This square is the initiator of the multifractal urban system. The generator then transforms the initial square into a central square of width $S_{1}=r_{1} \times L$ and $N=4$ surrounding smaller squares of width $S_{0}=r_{0} \times L$ such that:

and

$$
r_{1}+2 r_{0}=1
$$

$$
S_{1}+2 S_{0}=\mathrm{L}
$$


The hierarchical nesting of urban centres results from this iterative construction: an additional (lower) hierarchical level of urban centres appears at each iteration step. The generator contains two hierarchical levels; the second iteration step adds a third hierarchical level; the third iteration step adds a fourth hierarchical level. From the second hierarchical level on, the number of centres is multiplied by a fixed factor when passing to the next level, which is reminiscent of the logic in Christaller's central place theory.

Figure 2. Iterative generation of a multifractal Sierpinski carpet
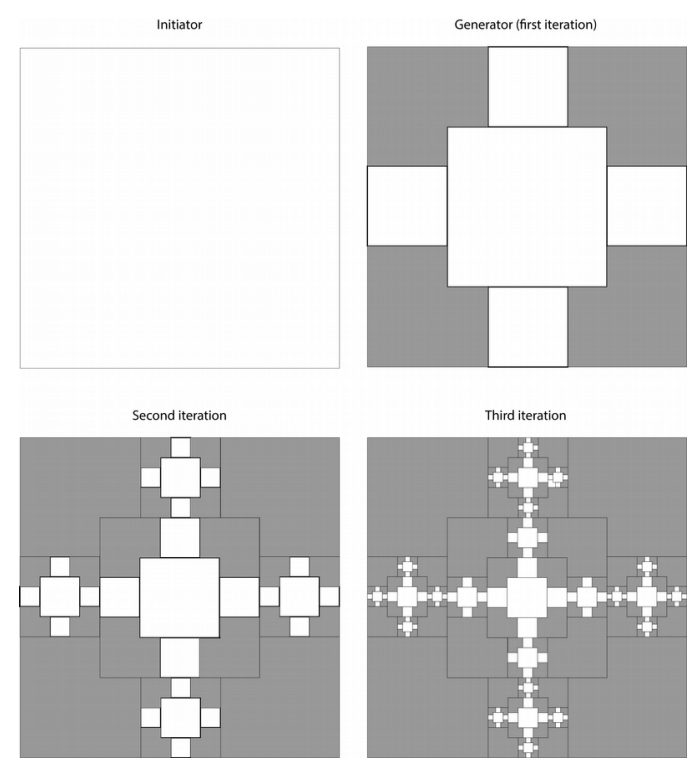

Figure 3. Code associated with each urban centre and each rural or green area.

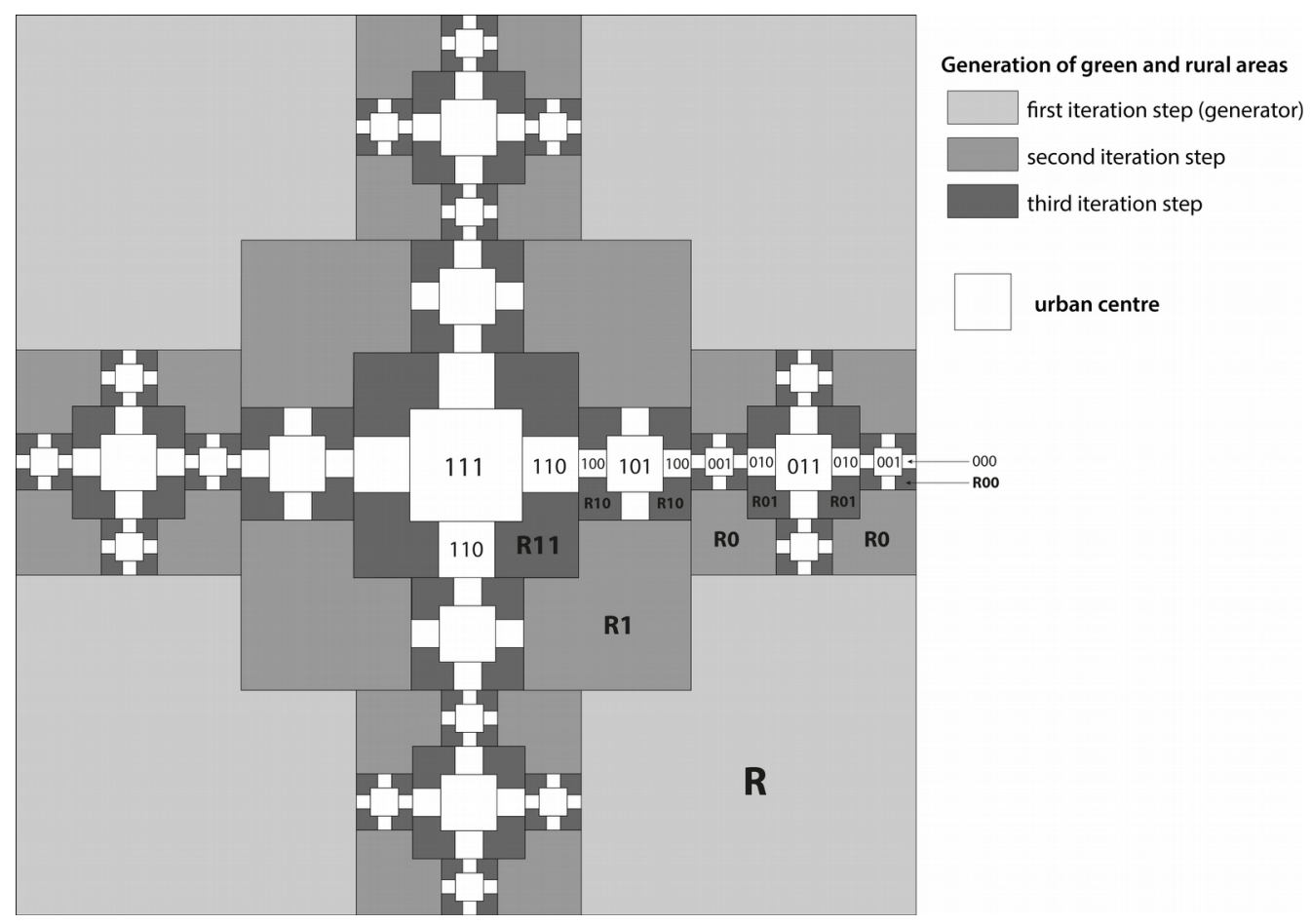


A numerical code is attributed to each urban centre according to its hierarchical level (Figure 3 and Table 1). Each digit of the code corresponds to an iteration step. From left to right: first iteration step, second iteration step, and third iteration step. Each " 1 " digit corresponds to the reduction factor $r_{1}$ and each " 0 " digit to the reduction factor $r_{0}$. This yields for instance the width $\left(r_{0} r_{1}^{2} \times L\right)$ for urban centres numbered "101".

Table 1. Hierarchy of urban centres in a four-level system in which the number of first-order subcentres $N=4$

\begin{tabular}{|l|l|l|}
\hline Functional level & Code & Number of centres \\
\hline $1^{\text {st }}$ & 111 & 1 \\
\hline $2^{\text {nd }}$ & 011 & 4 \\
\hline $3^{\text {rd }}$ & 101 and 001 & 20 \\
\hline $4^{\text {th }}$ & $110,100,010$, and 000 & 100 \\
\hline
\end{tabular}

Table 2. Codes, functional levels, and sizes of urban centres for a size $L$ of the region under study equal to $1000-N=4, r_{1}=1 / 2$ and $r_{0}=1 / 4$

\begin{tabular}{|l|c|c|l|c|}
\hline Code & $\begin{array}{c}\text { Functional } \\
\text { level }\end{array}$ & $\begin{array}{c}\text { Level of the nearest } \\
\text { higher-level centre }\end{array}$ & $\begin{array}{c}\text { Square } \\
\text { width }\end{array}$ & $\begin{array}{c}\text { Number of } \\
\text { centres }\end{array}$ \\
\hline 111 & 1 & & 125 & 1 \\
\hline 011 & 2 & 1 & 62.5 & 4 \\
\hline 101 & 3 & 1 & 62.5 & 4 \\
\hline 110 & 4 & 1 & 62.5 & 4 \\
\hline 001 & 3 & 2 & 31.25 & 16 \\
\hline 010 & 4 & 2 & 31.25 & 16 \\
\hline 100 & 4 & 3 & 31.25 & 16 \\
\hline 000 & 4 & 3 & 15.625 & 64 \\
\hline
\end{tabular}

Because the generator combines two reduction factors, the area of each centre depends on its relative position, i.e. its distance from higher-level centres (Table 2). As a consequence, the area of urban centres of different hierarchical levels may be the same whereas centres belonging to the same hierarchical level may have different areas. This differs from Christaller's central place theory but corresponds to the empirical observation that centres of the same functional level are larger when they are located in the vicinity of a big city and smaller when they are located in low-density zones.

\subsection{Nested and connected green and rural areas}

Rural and green areas are encoded according to the iteration step at which they were generated (Table 3 and Figure 3). As with urban centres, green and rural areas of different hierarchical levels may be the same size and green and rural areas belonging to the same hierarchical level may be different sizes. 
Table 3. Codes, hierarchical levels, and sizes of green and rural areas for a size $L$ of the region under study equal to $1000-N=4, r_{1}=1 / 2$, and $r_{0}=1 / 4$

\begin{tabular}{|l|c|c|c|c|}
\hline Code & Functional level & $\begin{array}{c}\text { Proportion of the surface } \\
\text { of the initiator }\end{array}$ & $\begin{array}{c}\text { Number of } \\
\text { elements }\end{array}$ & $\begin{array}{c}\text { Proportion of the surface of the } \\
\text { initiator occupied by each element }\end{array}$ \\
\hline $\mathrm{R}$ & 1 & $50 \%$ & 4 & $12.5 \%$ \\
\hline $\mathrm{R} 1$ & 2 & $12.5 \%$ & 4 & $3.125 \%$ \\
\hline $\mathrm{R} 0$ & 2 & $12.5 \%$ & 16 & $0.78125 \%$ \\
\hline $\mathrm{R} 11$ & 3 & $3.13 \%$ & 4 & $0.7825 \%$ \\
\hline $\mathrm{R} 10$ & 3 & $3.13 \%$ & 16 & $0.195625 \%$ \\
\hline $\mathrm{R} 01$ & 3 & $3.13 \%$ & 16 & $0.195625 \%$ \\
\hline $\mathrm{R} 00$ & 3 & $3.13 \%$ & 64 & $0.04890625 \%$ \\
\hline
\end{tabular}

\subsection{Spatial distribution of housing: hierarchical nesting of density gradients}

Figure 4. Two contrasted spatial distributions of housing - Number of housing units $v=1000000$, number of sub-centres $N=4$.

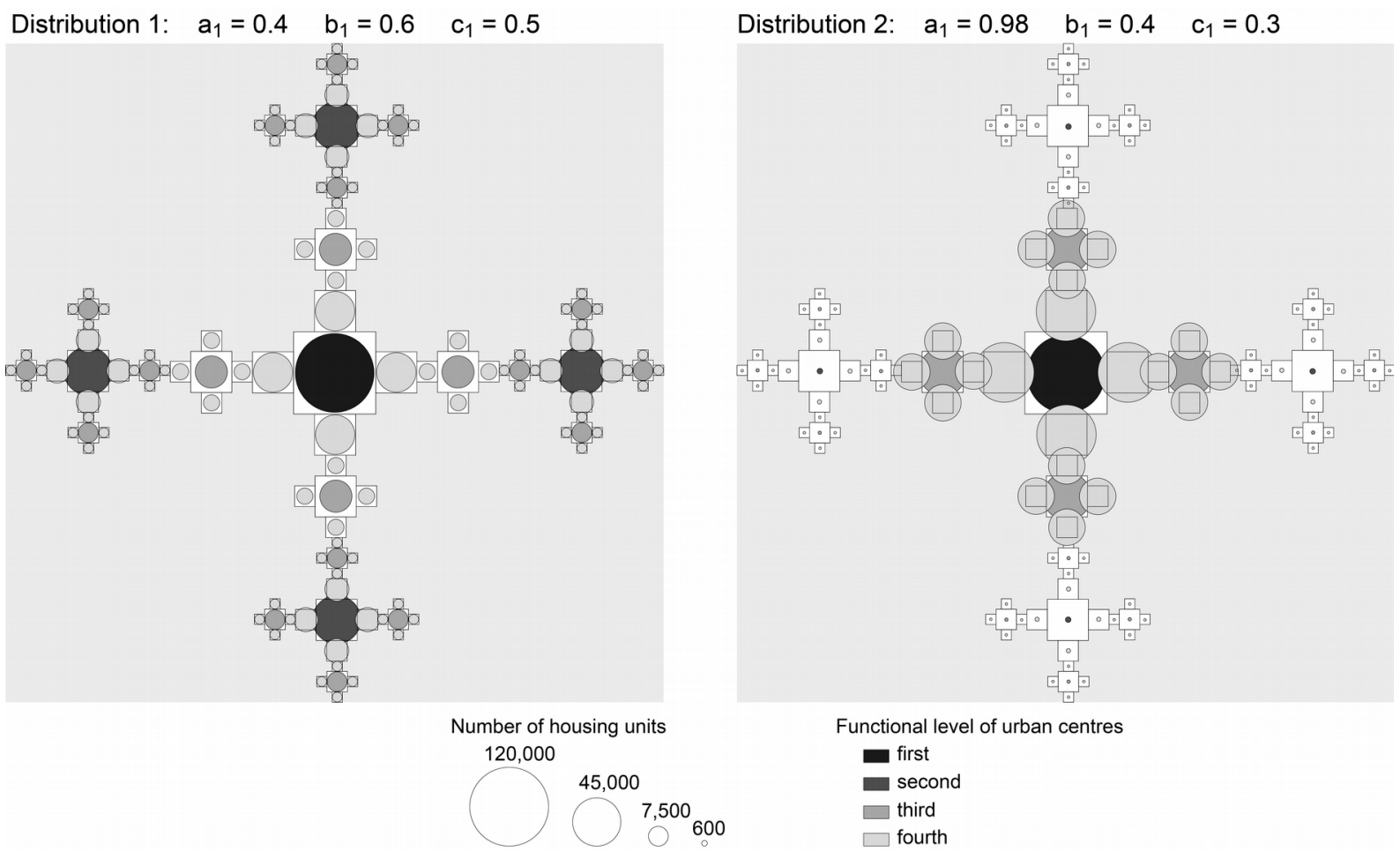

The whole urban region contains a given number $v$ of housing units. At each iteration step, a given share of those $v$ housing units is allotted to the urban centres. This share is noted $\alpha$ at the first iteration step, $\beta$ at the second iteration step, and $\gamma$ at the third iteration step ( $\alpha, \beta$, and $\gamma$ values lie between 0 and 1 ). Thus at the first iteration step, $\alpha v$ housing units are located in the urban squares whereas the very rural areas, coded "R", have $(1-\alpha) v$ housing units. At the second iteration step, the urban squares contain $\alpha \beta v$ housing units whereas the green and rural areas that have appeared, coded "R0" and "R1", contain $\alpha(1-\beta) v$ housing 
units. By the same logic at the third iteration step, the urban squares contain $\alpha \beta \gamma v$ housing units whereas the green and rural areas coded "R00", "R01", "R10" and "R11", contain $\alpha \beta$ (1 $-\gamma) v$ housing units.

Then at each iteration step, the whole stock of housing units in the urban centres, for instance $\alpha \beta \gamma v$ at the third iteration step, is dispatched among the urban centres according to their hierarchical code. For this, weighting factors are introduced. Factor $a$ corresponds to the first digit of the code, factor $b$ to the second digit, and factor $c$ to the third digit. The subscript 1 of each weighting factor corresponds to the digit " 1 " code and conversely, the subscript 0 corresponds to the digit " 0 " code. In order to maintain the total number of housing units $v$, the weights are normalized:

$$
\begin{aligned}
& a_{1}+N a_{0}=1 \\
& b_{1}+N b_{0}=1 \\
& c_{1}+N c_{0}=1
\end{aligned}
$$

On this basis, the choice of the weighting factor values enables us to define a spatial distribution of housing that follows a defined planning strategy (Figure 4). If $a_{1}>b_{1}>c_{1}$ more housing units are concentrated in urban centres for which the first code digit is 1 . Contrarily, a higher $b_{1}$ value reinforces the weight of second-order central places 011 and 010 and, at the same time, centres 111 and 110 remain populated. Hence housing density can differ for urban centres of the same surface area but different functional levels.

\section{From theory to application: Fractalopolis}

For real world applications, the GIS-based software application Fractalopolis has been developed to create multifractal development scenarios. An example of its use is given for the metropolitan area of Besançon, eastern France (203,000 inhabitants), which encompasses a central urban area (117,000 inhabitants) and its commuter belt. Data used for the application as well as values of parameters chosen for the multifractal development scenario are described in the Mendeley Data repository linked to this paper. The executable jar file of Fractalopolis 1.0 and the multifractal development scenario are available from: https://sourcesup.renater.fr/fractalopolis/.

\subsection{Creation of a multifractal development plan}

The creation of a plan starts with a cartographic representation of the region under study. For this, input data are six shapefiles. The first shapefile contains buildings (represented by polygons). The second shapefile contains public transport stations (tram, regional trains and Rapid Transit Bus) represented by points. The third shapefile contains shops and services (represented by points). The fourth shapefile contains leisure facilities and green areas represented by points. The fifth shapefile contains non-developable areas represented by polygons. Finally, the sixth shapefile contains the current number of housing units in each local community. In Fractalopolis, the number of housing units per community is proportional to the built-up area in the community in question. This enables the number of housing units in each square of a multifractal plan to be counted.

Two types of zone are distinguished in Fractalopolis, those available for urbanization (planned urban centres) and those for which only weak development or no development at all is permitted (areas located outside the planned centres). The number of sub-centres, the size 
parameters $r_{0}$ and $r_{1}$, and the number of functional levels (usually three or four) are chosen specifically for each real world case study.

The initiator of the plan is a quadratic area of size $L$ placed on the region under study (Figure 5a). Then the creation of the plan follows an iterative logic based on the use of Iterative Function Systems (Barnsley 1988). The generator of a plan usually contains a central large square of a chosen size $S_{1}=r_{1} \times L$ centred on the existing main urban centre and $N$ squares of size $S_{0}=r_{0} \times L$ centred on second-order urban centres (Figure 6). Then the IFS chosen for creating a multifractal development plan (called macro IFS in Fractalopolis) is iteratively applied until the smallest squares cover neighbourhoods. At this iteration step, the side length of the smaller squares ranges approximately from $500 \mathrm{~m}$ to $300 \mathrm{~m}$. In order to generate built patterns at finer scales, Fractalopolis offers the possibility of defining another IFS specifically for microscopic scales. In the application by Yamu and Frankhauser (2015), the size of squares generated by such a micro IFS ranges from $342 \mathrm{~m}$ to $21 \mathrm{~m}$.

Figure 5. Initiatior and generator chosen for the multifractal development plan of the metropolitan area of Besançon (eastern France). Red dots: public transport stations. Grey: non-developable areas.
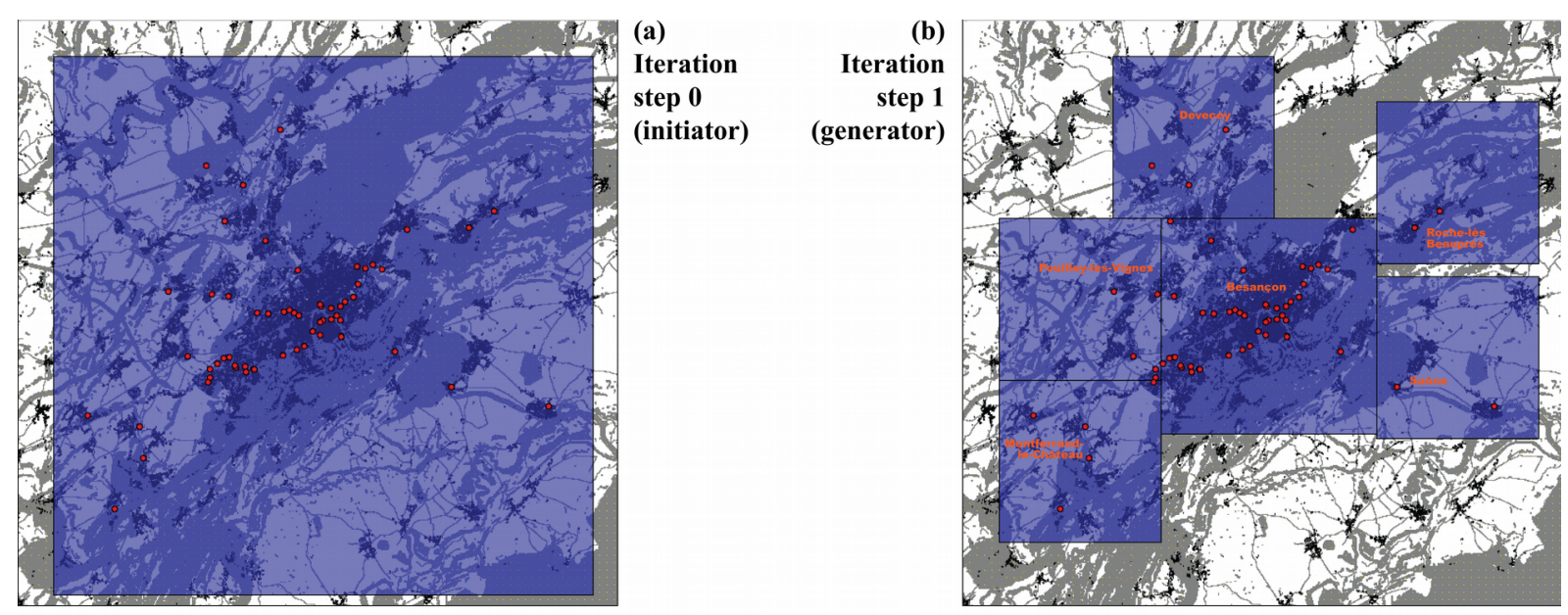

Figure 6. Setting an IFS in Fractalopolis 1.0 (screenshot). The square that is the main centre has rank number 1 and the squares that are the sub-centres have rank number 0 . 


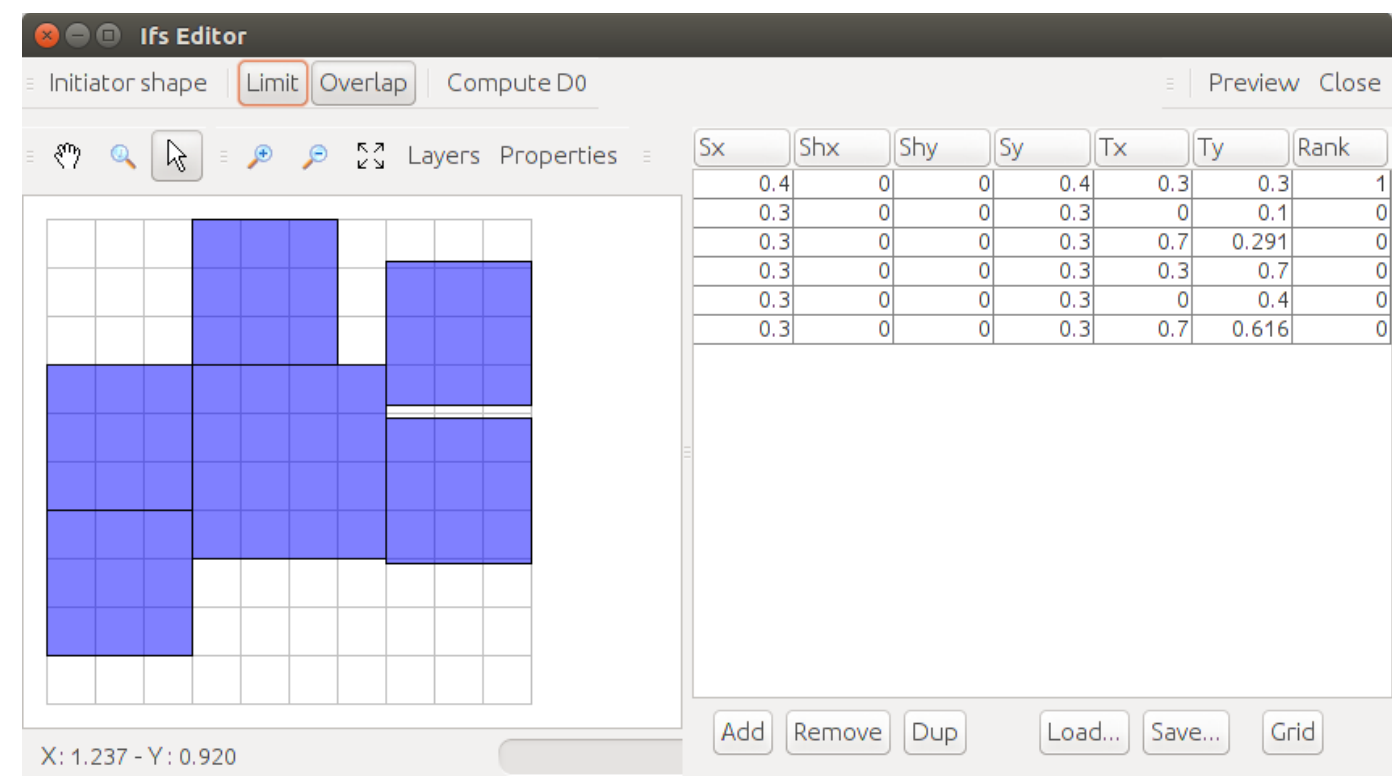

In the example of Besançon's metropolitan area, the generator of the multifractal plan contains one main centre (first functional level) and five sub-centres (second functional level) (Figure 5b). The difference in the size of the elements of the generator is small in order to match the spatial configuration of the study area. The main centre is placed on Besançon's inner city and the five sub-centres are placed on periurban communities well-served by the public transport network: Saône, Pouilley-les-Vignes, Monferrand-le-Château, Devecey, and Roche-lès-Beauprés.

Figure 7 shows the multifractal configuration resulting from the replication of the generator at the second and third iteration steps.

Figure 7. Multifractal configuration resulting from the strict replication of the generator. Grey: nondevelopable areas. Red dots: public transport stations. Grey: non-developable areas.
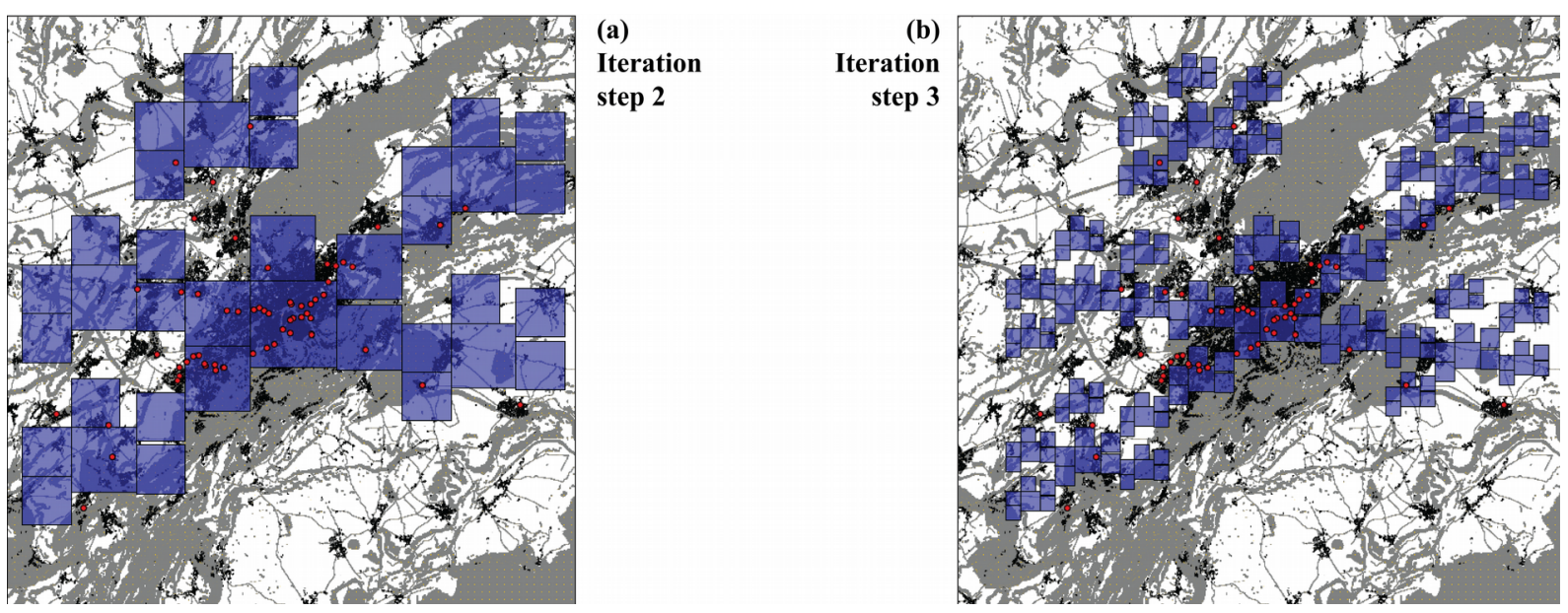

The geometrical pattern of Figure 7 has to be relaxed in order to correspond to the location of existing urban centres. For this, several squares were moved manually from their position set initially by the generator. By fractal logic, squares cannot overlap one another in Fractalopolis. Besides, rules have to be followed when moving squares: 
1) Centres of the highest levels must be served by main public transport axes (the backbone of the urban system is the public transport network).

2) Green alleys and green corridors must be preserved. By fractal logic, squares cannot overlap areas outside the centres created at previous iteration steps (i.e. mainly green and rural areas) in Fractalopolis. This ensures both the preservation of connected open spaces (i.e. ecological networks made-up of large and small patches), and the penetration of green areas into built-up areas at several nested scales. At the first and even second iteration steps of the creation of a multifractal plan, the squares representing urban centres are large and may contain non-developable areas. Then, in the course of iterations, the squares become smaller and they can be placed so as to preserve non-developable areas.

3) Good access to shops and services as well as to green areas and leisure facilities has to be ensured. For this, information about the suitability of each square is given by a colour code in Fractalopolis (see section 4.2 and Figure 8). Each time a square is moved, its access values are automatically updated.

Figure 8. Suitability of each planned centre of Figure 7b (screenshot from Fractalopolis 1.0). The properties of a given centre can be displayed by clicking on the targeted centre.

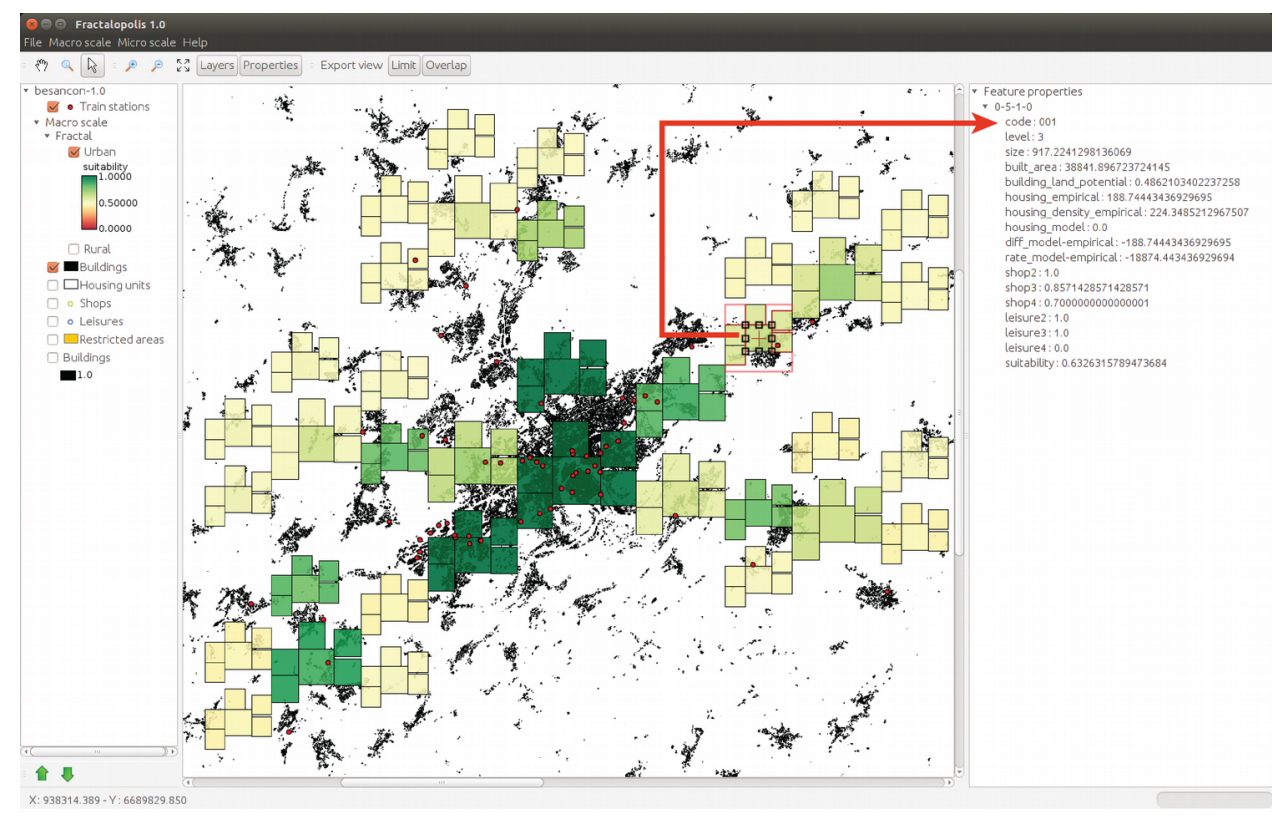

By all these rules, sub-centres of the third functional level were placed adequately around Besançon's inner city at the second iteration step with respect to the location of public transport stations (see Figure 9a and compare it with Figure 7a). At the third iteration step, the position of the squares was chosen mainly with respect to the suitability of developing each square as well as non-developable area. As a result, squares overlap a smaller amount of nondevelopable areas in Figure 9b than in Figure 7b. Moreover, the suitability of squares in Figure 10 is often higher than the suitability of squares in Figure 8.

Figure 9. A multifractal development plan of the metropolitan area of Besançon (eastern France). Red dots: public transport stations. Grey: non-developable areas. 

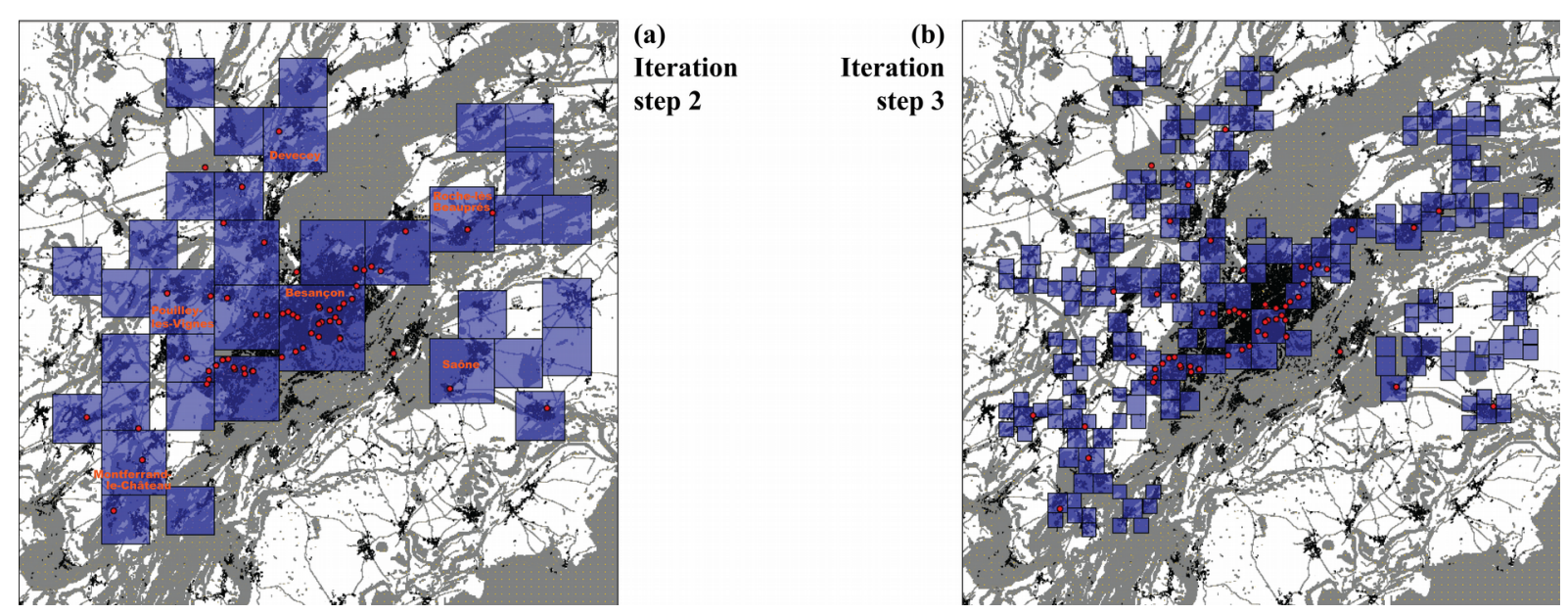

Finally, the multifractal plan exhibits the following characteristics: axial urban development along the public transport network axes; planned centres are interconnected except for a separation between Besançon and Saône resulting from the presence of non-developable areas (steep slopes and protected natural areas); areas outside planned centres are also well connected, thus the fragmentation of green and natural areas is avoided; green sectors not planned for urban development penetrate the urban agglomeration as far as Besançon city centre.

Figure 10. Suitability of each planned centre of Figure 9b (screenshot from Fractalopolis 1.0).

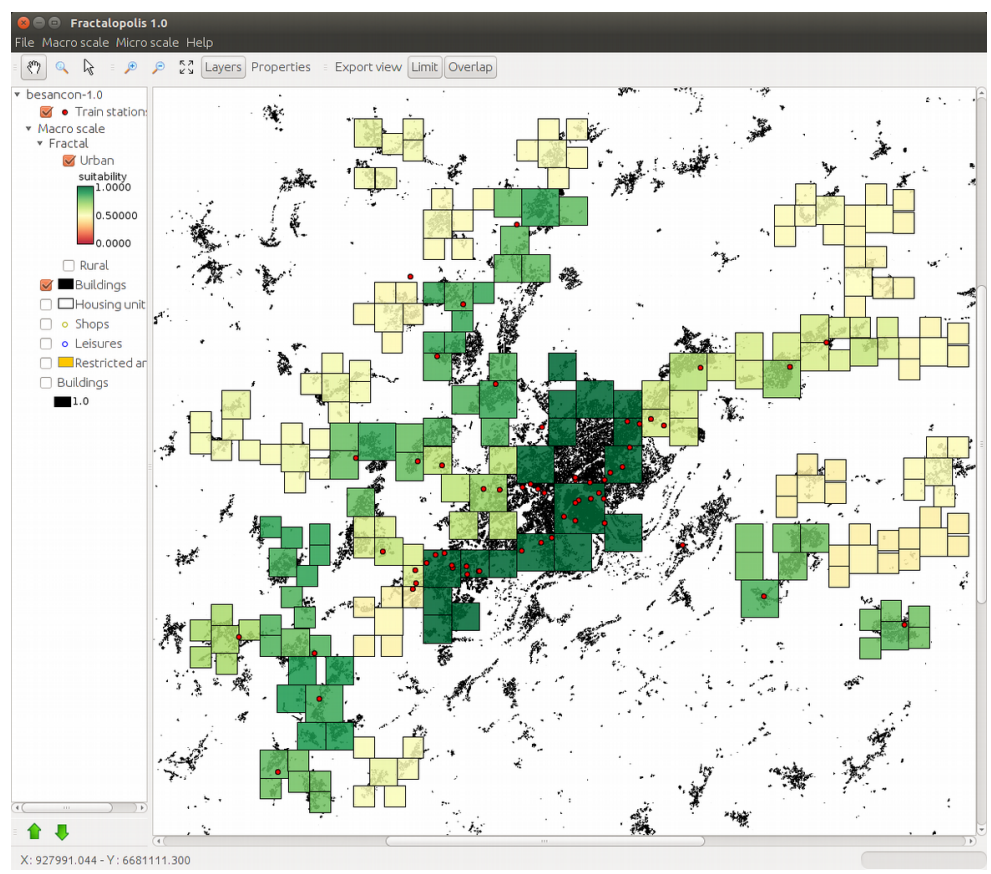

\subsection{Evaluation of the suitability of each planned urban centre for future development}

Here we concentrate exclusively on access to urban facilities, green areas, and leisure facilities although Fractalopolis can take other morphological constraints into account. Accessibility rules for assessing a multifractal development plan generated with a macro IFS 
are specific (see subsections below) and differ from the rules used for assessing accessibility in built patterns generated with a micro IFS. Assessment rules used at such a fine scale are presented in Yamu and Frankhauser (2015).

\subsubsection{Access to shops and services}

Shops and services are represented by points characterized by their type (e.g. bakery, school, hospital, library, etc.) and how often they are potentially used by inhabitants (daily, weekly, monthly, and rarely). One assumption in Fractalopolis is that the inhabitants of a given urban centre frequent the shops and services located within a defined catchment area that contains the urban centre under consideration. This catchment area corresponds to the square generated at the iteration step preceding the iteration step at which the considered urban centre was generated. For instance, in a plan at the third iteration step, the catchment area of shops and services frequented monthly is the initiator of the plan (iteration step 0); the catchment area of shops and services frequented weekly is the square generated at the first iteration step; the catchment area of shops and services frequented daily is the square generated at the second iteration step. In Figure 11, the delineations of areas located outside the planned centres correspond to the catchment areas of daily facilities (level 3 areas), weekly facilities (level 2 areas), and monthly facilities (level 1 areas), respectively.

Figure 11. Functional levels in the multifractal plan. Numbers in red and orange are the codes of the planned centres chosen for priority development.

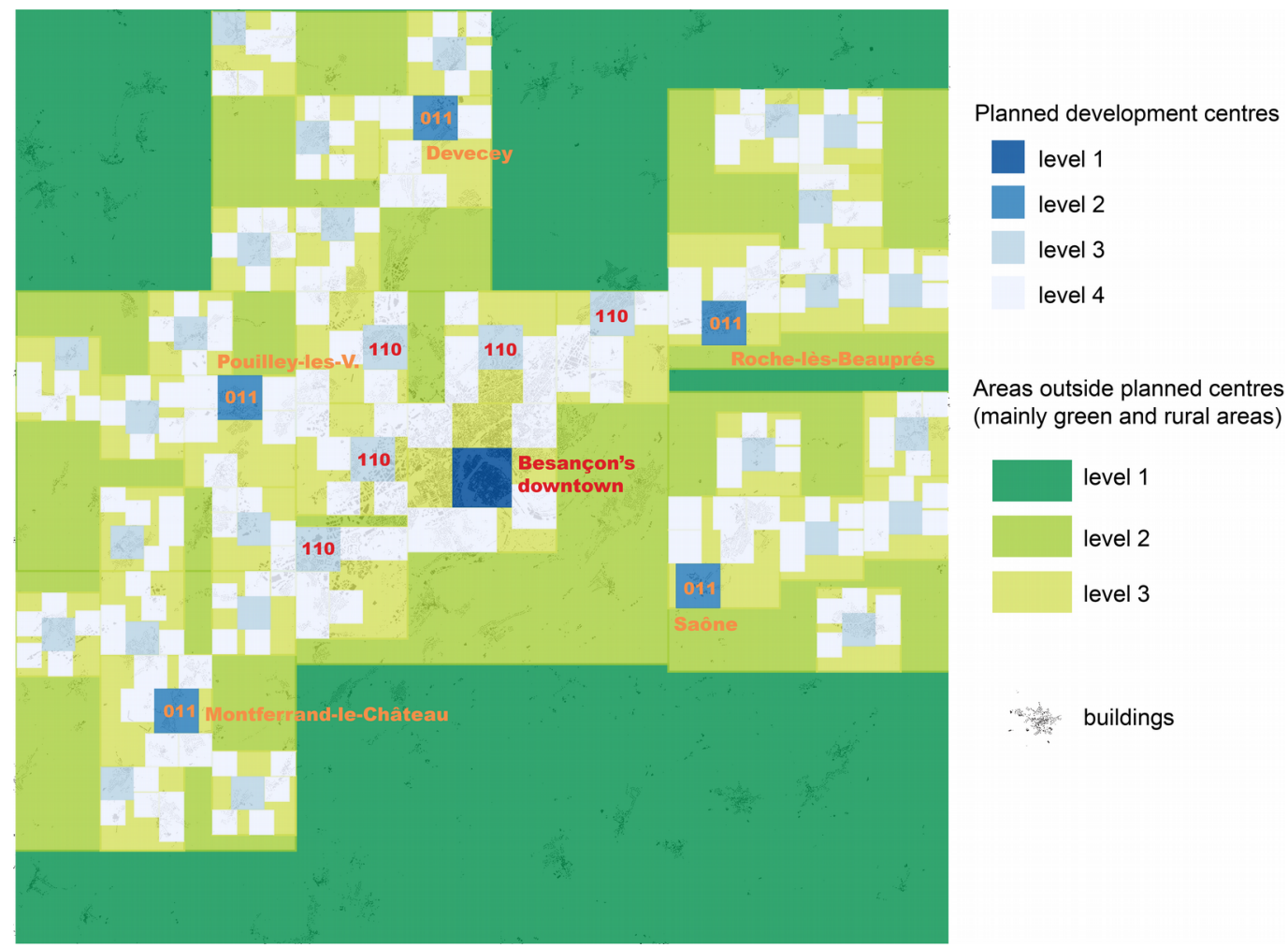

For rare or monthly frequencies of use, only the diversity of types of shops and services is assessed. The more diverse the types of shops and services within the catchment area or an urban centre, the better the evaluation of access to shops and services for the frequency of use under consideration. On this basis, the assessment rule is:

$S_{\text {rarely }}=\operatorname{MIN}\left[\left(\delta_{\text {zone }}(\right.\right.$ rarely $) / \delta_{\text {satis }}($ rarely $\left.\left.)\right) ; 1\right]$ 
$\mathrm{S}_{\text {monthly }}=\operatorname{MIN}\left[\left(\delta_{\text {zone }}(\right.\right.$ monthly $) / \delta_{\text {satis }}($ monthly $\left.\left.)\right) ; 1\right]$

where $\delta_{\text {zone }}$ corresponds to the number of different types of shops and services with the considered frequency of use within the catchment area of the urban centre under consideration. $\delta_{\text {satis }}$ corresponds to the number of different types corresponding to maximum satisfaction for the inhabitants.

For weekly or daily frequencies of use, both the diversity $\delta$ and the number $n$ of shops and services is assessed:

$\mathrm{S}_{\text {weekly }}=\left[\operatorname{MIN}\left[\left(\delta_{\text {zone }}(\right.\right.\right.$ weekly $) / \delta_{\text {satis }}($ weekly $\left.\left.\left.)\right) ; 1\right]\right] \times\left[\operatorname{MIN}\right.$ [ ( $\mathrm{n}_{\text {zone }}($ weekly $) / \mathrm{n}_{\text {satis }}($ weekly $\left.\left.)\right) ; 1\right]$ ]

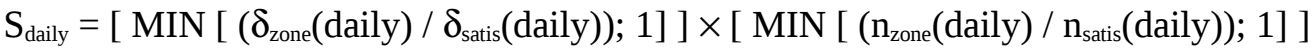

Each centre is therefore characterized by four evaluation values between 0 and 1 , one for each of the rules, with value 1 corresponding to the maximum evaluation. An example of appropriate values for $\delta_{\text {satis }}$ and $n_{\text {satis }}$ is given in the Mendeley Data repository linked to this paper.

\subsubsection{Access to leisure facilities and green areas}

Leisure facilities and green areas are also represented by points. Each dot is characterized by its type (e.g. swimming pool, tennis court, square, forest, etc.) and its potential frequency of use by the inhabitants (daily, weekly, monthly, and rarely). As with shops and services, the inhabitants of a given urban centre frequent the leisure facilities and green areas located within the corresponding catchment area. Assessment rules are also identical, except that only the diversity of types of leisure facilities and green areas (noted छ) is taken into account but not the number of leisure facilities and green areas.

$$
\begin{aligned}
& \mathrm{G}_{\text {rarely }}=\operatorname{MIN}\left[\left(\xi_{\text {zone }}\left(\text { rarely) } / \xi_{\text {satis }}(\text { rarely })\right) ; 1\right]\right. \\
& \mathrm{G}_{\text {monthly }}=\operatorname{MIN}\left[\left(\xi_{\text {zone }} \text { (monthly) } / \xi_{\text {satis }}\right.\right. \text { (monthly)); 1] } \\
& \left.\left.\mathrm{G}_{\text {weekly }}=\operatorname{MIN} \text { [ ( } \xi_{\text {zone }}(\text { weekly }) / \xi_{\text {satis }}(\text { weekly })\right) ; 1\right] \\
& \left.\mathrm{G}_{\text {daily }}=\operatorname{MIN} \text { [ ( } \xi_{\text {zone }}\left(\text { daily) } / \xi_{\text {satis }}(\text { daily })\right) ; 1\right]
\end{aligned}
$$

An example of appropriate values for $\xi_{\text {satis }}$ is given in the Mendeley Data repository linked to this paper.

\subsubsection{Aggregation rules}

In order to obtain synthetic evaluations of the suitability of each centre planned for development, two sets of aggregation rules have been defined. Formally, aggregation rules are weighted averages. The first set of aggregation rules enables the synthetic evaluation $\mathbf{F}$ of access to shops and services and leisure facilities and green areas having the same frequency of use for each urban centre. For instance, evaluation of access to shops and services and leisure facilities and green areas used daily for first-level urban centres is:

$F_{\text {daily[1] }}=g_{\text {daily[1] }} G_{\text {daily }}+S_{\text {daily[1] }} S_{\text {daily }}$

where $S_{\text {daily[1] }}$ is the weight of shops and services frequented daily and $g_{\text {daily[1] }}$ is the weight of leisure facilities and green areas frequented daily. The subscript number (here [1]) indicates the functional level of the centre under consideration (here, the first functional level). 
The second series of aggregation rules enables the synthetic evaluation $\mathbf{A}$ of access to all types of facilities for each planned centre. For instance, the evaluation A for a first-level centre is:

$$
A_{[1]}=f_{d[1]} F_{\text {daily[1] }}+f_{w[1]} F_{\text {weekly[1] }}+f_{m[1]} F_{\text {monthly[1] }}
$$

where $f_{d[1]}, f_{w[1]}$, and $f_{m[1]}$ are the weights of facilities (shops and services as well as leisure facilities and green areas) frequented daily, weekly, and monthly, respectively.

Weights involved in the aggregation rules represent the relative importance of each type of facility for the inhabitants, according to the functional level of the urban centre under consideration. Weights have to be chosen in order to reinforce to a greater or lesser degree the functional hierarchy of the spatial system modelled. For instance, greater importance can be attributed to access to shops and services than to green areas and leisure facilities for people living in urban centres of the first functional level. Conversely, easy access to green areas and leisure facilities can be considered more important than easy access to shops and services for people living in urban centres of the fourth functional level (i.e. periurban centres). The relative importance of shops and services versus green areas and leisure facilities may also vary with the frequency of recourse under consideration. For instance, for urban centres of the fourth functional level, access to green areas and leisure facilities is far more important than access to shops and services when considering monthly frequencies of use whereas the two are equally important when considering daily frequencies of use. In contrast, for urban centres of the first functional level, the relative importance of access to shops and services versus access to green areas is almost the same whatever the frequency of recourse under consideration. An example of appropriate weights is given in the Mendeley Data repository linked to this paper.

If the urban centres chosen for development have a shortfall of facilities, it is possible to test whether it is worth creating new shops or services by modifying the corresponding GIS-layer. Ideally, planned centres characterized by low suitability can be developed on condition that new shops, services, or leisure infrastructures are created, especially near public transport stations.

\subsection{Spatial distribution of housing to be constructed in future}

Another module of Fractalopolis is for analysing the spatial distribution of housing (housing model - see section 3.3). This module enables users to spatially distribute residential growth (construction of new housing units) and to quantify the discrepancy between the plan and the initial situation.

First, the initial number of housing units is counted by Fractalopolis for each planned centre at each iteration step. In case of Besançon's metropolitan area, the number of housing units counted in 2011 in the initiator of the plan (iteration step 0) is $v_{0}=98770$. At the third iteration step, as the size of the squares diminishes, only 59100 housing units existing in 2011 are located within a planned centre (Table 4) and 39677 housing units are located outside any planned centre. Indeed, the initial spatial configuration of the study area is far from multifractal. Even so, new urban developments in the planned centres will make it more multifractal and the functional hierarchy will be reinforced.

We imagine the construction of 1120 housing units each year over a period of 15 years, making a total of 16800 housing units. Thus in 2026, the number of housing units in the initiator will be $v_{1}=98770+16800=115570$. This is consistent with the residential growth targeted in the local development plan for the study area. The housing model of Fractalopolis 
helps us to define how to spatially distribute those 16800 new housing units. First, we set that no housing units are to be constructed outside the planned centres. For this, parameters $\alpha, \beta$, and $\gamma$ of the housing model (see section 3.3) have been suitably chosen (Table 4).

Table 4. Total number of housing units in the planned centres and settings of values for parameters $\alpha$, $\beta$, and $\gamma$ of the housing model

\begin{tabular}{|c|c|c|c|c|}
\hline & \multicolumn{2}{|c|}{ Number of housing units in the planned centres } & \multirow{2}{*}{$\begin{array}{c}\text { Calculation of } \\
\text { parameters }\end{array}$} & \multirow{2}{*}{$\begin{array}{c}\text { Value of } \\
\text { parameters }\end{array}$} \\
\hline & $\begin{array}{l}\text { Initial number } \\
\text { (year 2011) }\end{array}$ & $\begin{array}{l}\text { Targeted number } \\
\text { (year 2026) }\end{array}$ & & \\
\hline $\begin{array}{l}\text { Iteration } \\
\text { step } 1\end{array}$ & $\alpha\left(v_{0}\right)=93100$ & $\alpha\left(v_{1}\right)=\alpha\left(v_{0}\right)+16800=109900$ & $\alpha=\alpha\left(v_{1}\right) /\left(v_{1}\right)$ & $\alpha=0.9515151$ \\
\hline $\begin{array}{l}\text { Iteration } \\
\text { step } 2\end{array}$ & $\alpha \beta\left(v_{0}\right)=84800$ & $\alpha \beta\left(v_{1}\right)=\alpha \beta\left(v_{0 €}\right)+16800=101600$ & $\beta=\alpha \beta\left(v_{1}\right) / \alpha\left(v_{1}\right)$ & $\beta=0.9244767$ \\
\hline $\begin{array}{l}\text { Iteration } \\
\text { step } 3\end{array}$ & $\alpha \beta \gamma\left(v_{0}\right)=59100$ & $\alpha \beta \gamma\left(v_{1}\right)=\alpha \beta \gamma\left(v_{0 €}\right)+16800=75900$ & $\gamma=\alpha \beta \gamma\left(v_{1}\right) / \alpha \beta\left(v_{1}\right)$ & $\gamma=0.74704724$ \\
\hline
\end{tabular}

Table 5. Values of parameters $a, b$, and $c$ of the housing model

\begin{tabular}{|l|l|l|}
\hline & Initial situation (year 2011) & \multicolumn{1}{|c|}{ Final situation (year 2026) } \\
\hline $\mathrm{a}_{1}$ & 0.7968 & 0.7500 \\
\hline $\mathrm{a}_{0}$ & 0.0406 & 0.0500 \\
\hline $\mathrm{b}_{1}$ & 0.5564 & 0.5600 \\
\hline $\mathrm{b}_{0}$ & 0.0887 & 0.0880 \\
\hline \hline$c_{1}$ & 0.4568 & 0.5000 \\
\hline$c_{0}$ & 0.1086 & 0.1000 \\
\hline
\end{tabular}

Figure 12. Number of housing units in each planned centre in 2011 (initial situation) and 2026 (targeted growth).

(a) Initial number of dwellings (year 2011)
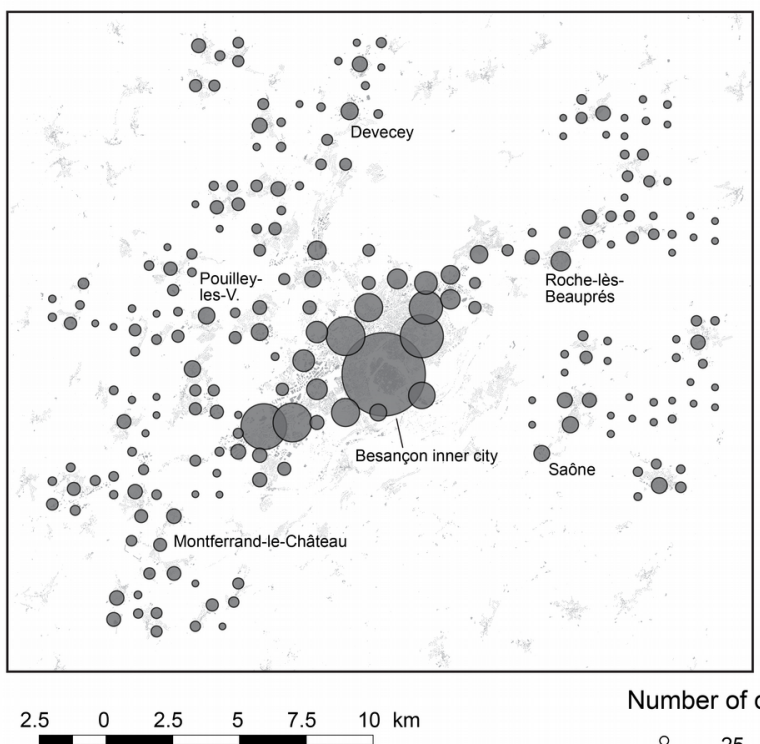

buildings (b) Targeted number of dwellings (year 2026)

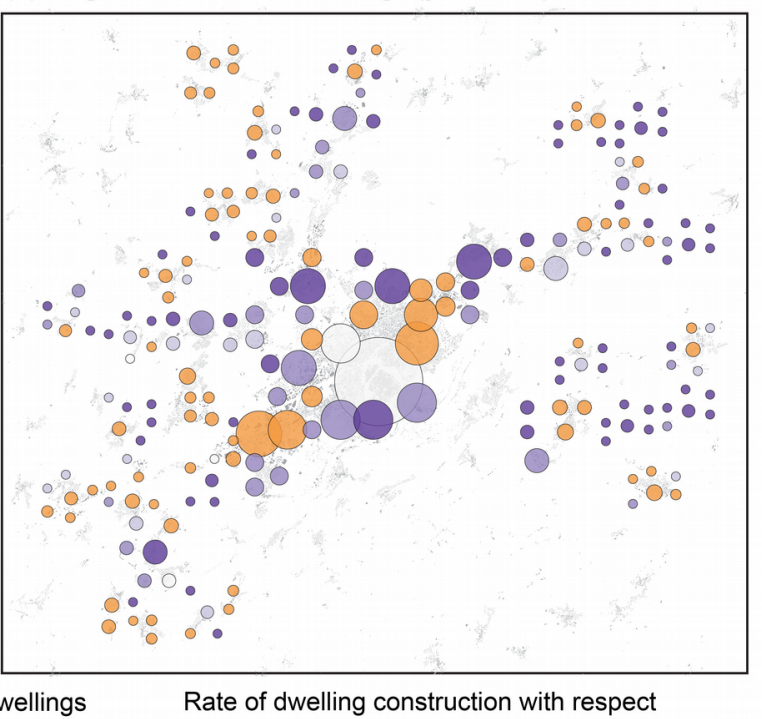

to the number of dwellings in 2011 (in \%)
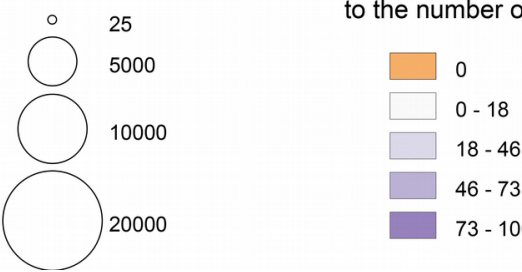
Values of parameters $a, b$, and $c$ of the housing model for the initial situation in 2011 (Table 5) are automatically calculated in Fractalopolis on the basis of the mean number of housing units in each type of planned centre at the third iteration step (see Appendix). Values of parameters $a, b$, and $c$ for the year 2026 have to be slightly different than for the year 2011 in order to accentuate the hierarchy in the size of the planned centres in 2026. In particular, we want the number of housing units in both the centres of the second functional level located in second peripheral ring around Besançon (code 011) and the centres of the third level located in the first peripheral ring around Besançon (code 110) to be higher in 2026 than in 2011 (see Figure 11 for the location of these centres). For this, appropriate values of parameters $a, b$, and $c$ of the housing model were set (Table 5).

Comparing the two maps in Figure 12 shows how residential growth in the targeted centres introduces more hierarchy into the settlement pattern although the centres coloured in orange contain more housing than recommended by the model. Comparison of Figure 11b with Figure 8 also shows that most of the residential growth will occur in centres that are more suitable for residential development. Where new facilities (shops and services, leisure infrastructures) are created, priority should be given to the third level centre located at the West of Besançon inner city as well as to the eastern peripheral route around Roche-lèsBeauprés. Besides, most very small peripheral centres of the fourth functional level are unsuitable because of a lack of shops and services for daily use; this shortage should be corrected.

\section{Conclusion}

In this paper, we have proposed a conceptual framework for designing multifractal urban or regional development plans that jointly respect five planning principles: hierarchical polycentric urban development; transit-oriented development; locally dense residential development; the penetration of green areas into built-up areas at several nested scales; the preservation of large interconnected networks of natural and green areas having various sizes.

This conceptual framework can be applied to real-world case studies using the GIS-based software application Fractalopolis (current version 1.0). Fractalopolis supports both the design of a multifractal plan for an urban region and the assessment of the suitability of developing each part of the region. It helps to define, step-by-step and interactively, where to create new housing and new facilities according to the integrated planning principles set out above. By linking scales in such a coherent way, it is possible to consider a metropolitan area as a whole when designing future development scenarios, while at the same time considering intermediate and local scales up that of lots. Moreover, it is possible to explore very detailed scenarios on intermediate or local scales for some parts of a study area while keeping to a less detailed level for other parts of the area under study. This has the additional benefit of simplifying data management.

Fractalopolis has been used here for designing a multifractal development plan for a French medium-sized metropolitan area, namely Besançon. The design of this multifractal plan was challenging because the area under study includes many natural and regulatory constraints (i.e. very extensive non-developable areas) and its initial spatial configuration (in 2011) is very far from any multifractal hierarchy. Moreover, the targeted residential growth until 2026 
was quite low (few new housing units have to be constructed), which precludes wholesale transformation of the spatial configuration of the area under study. Nevertheless, the use of Fractalopolis enabled us to propose a realistic "soft" transformation of Besançon's metropolitan area that meets the five planning objectives set out above and makes the region more multifractal. This illustrates how the integrated approach to multifractal urban and regional planning can be adapted to any pre-existing spatial configuration without having to start from a blank slate. This also illustrates how the use of Fractalopolis helps to link efficiently housing and facilities in urban and regional planning.

Of course, other multifractal development plans could be imagined in response to a modification of the parameters of the housing model, a change of the IFS, different requirements with regard access to facilities, or even supplementary planning constraints (e.g. morphological constraints). It would also be possible to apply the model to the case of shrinking cities in order to determine places where housing should be removed and eventually replaced by green and natural areas. The short-term objective is to include Fractalopolis in a real-world planning process so as to assess its usefulness. As suggested by Yamu, De Roo, and Frankhauser (2016), the step by step design of a multifractal plan can be included in a participatory planning process. In this context, environmental impacts (e. g. volume of vehicle traffic, local climate, functionnal connectivity of ecological habitats) of a multifractal plan created with Fractalopolis should be assessed. Last but not least, another objective would be to enrich the model by 1 ) including employment zones offering an appropriate number of jobs in the vicinity of residential areas; 2) providing for a three dimensional representation of the housing model; and 3) linking the number of housing units in each planned centre with landuse indexes usually considered in urban and regional planning.

Acknowledgements. The software application Fractalopolis was developed as part of the French PREDIT 4 programme (research programme on innovation in transport), funded by the French Ministry of Ecology, Energy, and Sustainable Development. The authors would like to thank Damien Roy (research laboratory ThéMA, Besançon, France) for his support with some of the GIS processing. 
Appendix. Number of housing units in the planned centres calculated by Fractalopolis 1.0 for a multifractal development scenario on Besançon's metropolitan area

First iteration step

\begin{tabular}{|c|c|c|c|c|c|}
\hline \multirow[b]{2}{*}{ Code } & \multicolumn{2}{|c|}{ Initial number (year 2011) } & \multicolumn{3}{|c|}{ Number given by the housing model (year 2026) } \\
\hline & $\begin{array}{l}\text { Mean number } \\
\text { in each centre }\end{array}$ & $\begin{array}{c}\text { Total } \\
\text { number }\end{array}$ & Calculation & $\begin{array}{l}\text { Mean number in } \\
\text { each centre }\end{array}$ & Total number \\
\hline 1 & 74182 & 74182 & $\alpha\left(v_{1}\right) a 1$ & 82425 & 82425 \\
\hline 0 & $\begin{array}{r}3782 \\
\text { MIN: } 2,754 ; \text { MAX: } 4,925\end{array}$ & 18912 & $\alpha\left(v_{1}\right) a 0$ & 5495 & 27475 \\
\hline
\end{tabular}

\section{Second iteration step}

\begin{tabular}{|c|c|c|c|c|c|}
\hline \multirow[b]{2}{*}{ Code } & \multicolumn{2}{|c|}{ Initial number (year 2011) } & \multicolumn{3}{|c|}{ Number given by the housing model (year 2026) } \\
\hline & $\begin{array}{l}\text { Mean number } \\
\text { in each centre }\end{array}$ & $\begin{array}{c}\text { Total } \\
\text { number }\end{array}$ & Calculation & $\begin{array}{l}\text { Mean number in } \\
\text { each centre }\end{array}$ & Total number \\
\hline 11 & 40926 & 40926 & $\alpha \beta\left(v_{1}\right) a 1 b 1$ & 42672 & 42672 \\
\hline 10 & $\begin{array}{r}5488 \\
\text { MIN: } 2 \text { 016; MAX: } 10145 \\
\end{array}$ & 27438 & $\alpha \beta\left(v_{1}\right) a 1 b 0$ & 6706 & 33528 \\
\hline 01 & $\begin{array}{r}1246 \\
\text { MIN: } 1,013 \text {; MAX: } 1,385 \\
\end{array}$ & 6228 & $\alpha \beta\left(v_{1}\right) a 0 b 1$ & 2845 & 14224 \\
\hline 00 & MIN: 7 ; MAX: 780 & 10153 & $\alpha \beta\left(v_{1}\right) a 0 b 0$ & 447 & 11176 \\
\hline
\end{tabular}

\section{Third iteration step}

\begin{tabular}{|c|c|c|c|c|c|c|}
\hline \multicolumn{7}{|c|}{. } \\
\hline \multirow[b]{2}{*}{ Code } & \multirow[b]{2}{*}{\begin{tabular}{|c|}
$\begin{array}{c}\text { Functional } \\
\text { level }\end{array}$ \\
\end{tabular}} & \multicolumn{2}{|c|}{ Initial number (year 2011) } & \multicolumn{3}{|c|}{ Number given by the housing model (year 2026) } \\
\hline & & $\begin{array}{l}\text { Mean number } \\
\text { in each centre }\end{array}$ & $\begin{array}{c}\text { Total } \\
\text { number }\end{array}$ & Calculation & $\begin{array}{l}\text { Mean number in } \\
\text { each centre }\end{array}$ & Total number \\
\hline 111 & 1 & 14307 & 14307 & $\alpha \beta \gamma\left(v_{1}\right) a 1 b 1 c 1$ & 15939 & 15939 \\
\hline 110 & 4 & MIN: 417 ; MAX: 3878 & 10253 & $\alpha \beta \gamma\left(v_{1}\right) a 1 b 1 c 0$ & 3188 & 15939 \\
\hline 101 & 3 & $\begin{array}{r}1334 \\
\text { MIN: } 375 \text {; MAX: } 4373\end{array}$ & 6672 & $\alpha \beta \gamma\left(v_{1}\right) a 1 b 0 c 1$ & 2505 & 12524 \\
\hline 100 & 4 & $\begin{array}{r}547 \\
\text { MIN: 8; MAX: } 3102 \\
\end{array}$ & 13663 & $\alpha \beta \gamma\left(v_{1}\right) a 1$ boc0 & 501 & 12524 \\
\hline 011 & 2 & $\begin{array}{r}389 \\
\text { MIN: 417; MAX: } 3878 \\
\end{array}$ & 1944 & $\alpha \beta \gamma\left(v_{1}\right) a 0 b 1 c 1$ & 1063 & 5313 \\
\hline 010 & 4 & $\begin{array}{r}139 \\
\text { MIN: } 0 \text {; MAX: } 376 \\
\end{array}$ & 3477 & $\alpha \beta \gamma\left(v_{1}\right) a 0 b 1 c 0$ & 213 & 5313 \\
\hline 001 & 3 & $\begin{array}{r}162 \\
\text { MIN: } 0 \text {; MAX: } 343 \\
\end{array}$ & 4048 & $\alpha \beta \gamma\left(v_{1}\right) a 0 b 0 c 1$ & 167 & 4175 \\
\hline 000 & 4 & MIN: 0 ; MAX: 278 & 4695 & $\alpha \beta \gamma\left(v_{1}\right) a 1 b 1 c 1$ & 34 & 4175 \\
\hline
\end{tabular}




\section{References}

Aguilera, A., Mignot, D. (2004). Urban sprawl, polycentrism and commuting, Urban Public Economic Review, 1, 92-113.

Aguilera, F., Valenzuela, L.M., Botequilha-Leitão, A. (2011). Landscape metrics in the analysis of urban land use patterns: a case study in a Spanish metropolitan area. Landscape and Urban Planning, 99, 226-238.

Angold, P. G., Sadler, J. P., Hill, M. O., Pullin, A., Rushton, S., Austin, K., Small, E., Wood, B., Wadsworth, R., Sanderson, R., Thompson, K. (2006). Biodiversity in urban habitat patches. Science of the Total Environment, 360, 196- 204.

Baldock, K.C.R., Goddard, M.A., Hicks, D.M., Kunin, W.E., Mitschunas, N., Osgathorpe, L.M., Potts, S.G., Robertson, K.M., Scott A.V., Stone G.N., Vaughan I.P., Memmott J. (2015). Where is the UK's pollinator biodiversity? The importance of urban areas for flower-visiting insects. Proceedings of th Royal Society $B$ (Biological Sciences), 282: 20142849.

Barnsley, M. (1988). Fractals Everywhere, Academic Press, New York.

Beatley, T. (2012). Green Cities of Europe. Global Lessons on Green Urbanism. Washington DC, Island Press.

Bontje, M. (2005). Facing the challenge of shrinking cities in East Germany: The case of Leipzig, GeoJournal, 61(1), 13-21.

Borgström, S. T., Elmqvist, T., Angelstam, P., Alfsen-Norodom, C. (2006). Scale mismatches in management of urban landscapes. Ecology and Society 11(2): 16. [online] http://www.ecologyandsociety.org/vol11/iss2/art16/

Bryant, M. (2006). Urban landscape conservation and the role of ecological greenways at local and metropolitan scales, Landscape and Urban Planning, 76(1-4), 23-44.

Calthorpe, P. (1993). The Next American Metropolis: Ecology, Community, and the American Dream. Princeton Architectural Press, New York.

Camagni, R., Gibelli, M. C. (1997). Développement urbain durable: quatre métropoles européennes à l'épreuve. La Tour d'Aigues, Editions de l'Aube.

Cavailhès, J., Frankhauser, P., Peeters, D., Thomas, I. (2004). Where Alonso meets Sierpinski: an urban economic model of a fractal metropolitan area, Environment and Planning A, 36 (8), 1471-1498.

Cavailhès, J., Frankhauser, P., Peeters, D., Thomas, I. (2010). Residential equilibrium in a multifractal metropolitan area, The Annals of Regional Science, 45(3), 681-704.

Cervero, R. (1996). Mixed land-uses and commuting: evidence from the American Housing Survey, Transportation Research Part A, 30(5), 361-377.

Cervero, R., Kockelman, K. (1997). Travel demand and the 3Ds: density, diversity, and design, Transportation Research Part D: Transport and Environment, 2(3), 199-219.

Christaller, W. (1933). Die zentralen Orte in Süddeutschland. Eine ökonomisch-geographische Untersuchung über die Gesetzmäßigkeit der Verbreitung und Entwicklung der Siedlungen mit städtischer Funktion. Wissenschaftliche Buchgesellschaft, Darmstadt 1980 (Reprint d. Ausg. Jena 1933).

Collinge, S. K. (1996). Ecological consequences of habitat fragmentation: Implications for landscape architecture and planning, Landscape and Urban Planning, 36(1), 59-77.

Conway, T. (2009). Local environmental impacts of alternative forms of residential developmen, tEnvironment and Planning B:Planning and Design, 36, 927-943.

Czamanski, D., Benenson, I., Malkinson, D., Marinov, M., Roth, R., Wittenberg, L. (2008). Urban sprawl and ecosystems—can nature survive? Int. Rev. Environ. Resour. Econ. 2, 321-366.

Duany, A., Plater-Zyberk, E., Speck, J. (2001). Suburban Nation: The Rise of Sprawl and the Decline of the American Dream. North Point Press, New York.

Eberstadt, R., Möhring, B., Petersen, R. (1910). Gross-Berlin. Ein Programm für die Planung der neuzeitlichen Grosstadt. Wasmuth, Berlin.

Fittkau, D. (2004). Beeinflussung regionaler Kaufkraftströme durch den Autobahnlückenschluß der A 49 KasselGießen. Zur empirischen Relevanz der "New Economic Geography" in wirtschaftsgeographischen Fragestellungen, PHD-thesis, Georg-August-University of Göttingen. 
Forman, R. T. T. (1995). Land Mosaics: The Ecology of Landscapes and Regions. University Press, Cambridge.

Franck, L.G., Pivo, G. (1994). Impacts of mixed use and density on utilization of three modes of travel: Singleoccupant vehicle, transit, and walking, Transportation Research Record, 1466, 44-52.

Frankhauser, P. (1994). La fractalité des structures urbaines. Anthropos, Paris.

Frankhauser, P. (2008). Fractal Geometry for Measuring and Modelling Urban Patterns. In S. Albeverio, D. Andrey, P. Giordano, \& A. Vancheri. The Dynamics of Complex Urban Systems, Springer, 213-243.

Frankhauser, P. (2015). From fractal urban pattern analysis to fractal urban planning concepts. In M. Helbich, J. J. Arsanjani, \& M. Leitner. Computational approaches for urban environments, geotechnologies and the environment, Springer, 13-48.

Fu, W., Liu, S., Degloria, S.D., Dong, S., Beazley, R. (2010). Characterizing the fragmentation-barrier effect of road networks on landscape connectivity: a case study in Xishuangbanna. Southwest China, Landscape and Urban Planning, 95, 122-129.

Fujita, M., Ogawa, H. (1982). Multiple equilibria and structural transition of nonmonocentric urban configurations, Regional science and Urban Economics, 12, 161-196.

Fujita, M., Thisse, J.F. (2002). Economics of Agglomeration. University Press, Cambridge.

Geurs, K. T., van Wee, B. (2006). Ex-post evaluation of thirty years of compact urban development in the Netherlands, Urban Studies, 43, 139-160.

Gurrutxaga, M., Lozano, P.J., Del Barrio, G. (2010). Assessing highway permeability for the restoration of landscape connectivity between protected areas in the Basque Country, Northern Spain, Landscape Research, 35, 529-550.

Hall, P. (1997). The future of the metropolis and its form, Regional Studies, 31(3), 211-220.

Howard, E. (1898). To-morrow: A Peaceful Path to Real Reform. Swan Sonnenschein \& Co, London.

Kong, F., Yin, H., James, P., Hutyra, L. R., He, H. S. (2014). Effects of spatial pattern of greenspace on urban cooling in a large metropolitan area of eastern China, Landscape and Urban Planning, 128, 35-47.

Krier, L. (1998). Architecture: Choice or Fate. Andreas Papadakis Publishers, London.

Krugman, P. (1995). Development, Geography and Economic Theory. The MIT Press, Cambridge MA.

Kuttler, W. (2011). Climate change in urban areas - Part 2: Measures, Environmental Sciences Europe, 23:21.

McMillen, D.P., Smith, S.C. (2003). The number of subcenters in large urban areas, Journal of Urban Economics, 53, 321-338.

Neuman, M. (2005). The Compact City Fallacy, Journal of Planning Education and Research, 25, 11-26.

Oliveira, J.A., Balaban, O., Doll, C.N.H., Peñaranda, R. M., Gasparatos, A., Iossifova, D., Suwa, A. (2011). Cities and biodiversity: perspectives and governance challenges for implementing the convention on biological diversity (CBD) at the city level. Biological Conservation, 144, 1302-1313.

Peeters, D., Caruso, G., Cavailhès, J., Thomas, I., Frankhauser, P., Vuidel, G., (2015). Emergence of leapfrogging from residential choice with endogenous green space: analytical results, Journal of Regional Science, 55(3): 491512.

Qureshi, S., Breuste, J. H. (2010). Chapter 27. Prospects of Biodiversity in the Mega-City of Karachi, Pakistan: Potentials, Constraints and Implications. In N. Muller, P. Warner and J. G. Kelcey (eds), Urban biodiversity and design, Conservation science and practice $n^{\circ}$, Wiley-Blackwell, 497-517.

Savard, J.-P., Clergeau, P., Mennechez, G. (2000). Biodiversity concepts and urban ecosystems. Landscape and Urban Planning, 48, 131-142.

Sachsen, T., Ketzler, G., Knörchen, A., Schneider, C. (2013). Past and future evolution of nighttime urban cooling by suburban cold air drainage in Aachen, Die Erde - Journal of the geographic Society in Berlin, 144(34), 274-289.

Salingaros, N. A. (2004). Connecting the Fractal City. PLANUM - The European Journal of Planning, 8(1), online: http://www.planum.net/planum-magazine 
Schmidt, R. (1912). Denkschrift betreffend Grundsätze zur Aufstellung eines General-Siedelungsplanes für den Regierungsbezirk Düsseldorf (rechtsrheinisch). Reprint herausgegeben vom Regionalverband Ruhr, Mitherausgeber Dieter Nellen, erschienen im Klartext Verlag (Oktober 2009).

Schwanen, T., Dijst, M., Dieleman, F. M. (2004). Policies for urban form and their impact on travel: The Netherlands experience. Urban Studies, 41(3), 579-603.

Siedentop, S., Fina, S., Krehl, A. (2016). Greenbelts in Germany’s regional plans-An effective growth management policy? Landscape and Urban Planning 145, 71-82.

Soga, M., Yamaura, Y., Aikoh, T., Shoji, Y., Kubo, T., Gaston, K. J. (2015). Reducing the extinction of experience: Association between urban form and recreational use of public greenspace, Landscape and Urban Planning 143, 69-75.

Tannier, C., Vuidel, G., Houot, H., Frankhauser, P. (2012). Spatial accessibility to amenities in fractal and non fractal urban patterns, Environment and Planning B: Planning and Design 39(5), pp. 801-819.

Tannier, C., Bourgeois, M., Houot, H., Foltête, J-C. (2016). Impact of urban developments on the functional connectivity of forested habitats: a joint contribution of advanced urban models and landscape graphs, Land Use Policy, 52, pp. 76-91.

Toger, M., Malkinson, D., Benenson, I., Czamanski, D. (2016). The connectivity of Haifa urban open space network. Environment and Planning B:Planning and Design, Vol. 43(5) 848-870.

von Haaren, C., Reich, M. (2006). The German way to greenways and habitat networks, Landscape and Urban Planning, 76, 7-22.

Vyn, R. J. (2012). Examining for Evidence of the Leapfrog Effect in the Context of Strict Agricultural Zoning, Land Economics, 88(3), 457-477.

Wissen Hayek, U., Efthymiou, D., Farooq, B., von Wirth, T., Teich, M., Neuenschwander, N., Grêt-Regamey, A. (2015). Quality of urban patterns: spatially explicit evidence for multiple scales, Landscape and Urban Planning, 142, 47-62.

Yamu, C., Frankhauser, P. (2015). Spatial accessibility to amenities, natural areas and urban green spaces: using a multiscale, multifractal simulation model for managing urban sprawl, Environment and Planning B: Planning and Design, 42(6), 1054-1078.

Yamu, C., De Roo, G., Frankhauser, P. (2016). Assuming it is all about conditions. Framing a simulation model for complex, adaptive urban space, Environment and Planning B: Urban Analytics and City Science, 43(6), 1019-1039. 